\title{
Fibrous structured catalytic beds for three-phase reaction engineering Hydrodynamics study in staged bubble columns
}

\author{
Volker Höller, Dagmar Wegricht, Lioubov Kiwi-Minsker, Albert Renken* \\ Swiss Federal Institute of Technology, CH-1015 Lausanne, Switzerland
}

\begin{abstract}
Woven fibrous materials are proposed as structured catalysts for three-phase catalytic reactors. The design of a catalytic bed arranged as a plate bubble column is discussed. The hydrodynamic parameters, like pressure drop and liquid hold-up were found to depend on the woven structure of the fibrous layers and are shown to be a function of the distance between the threads in the fibres. (C) 2000 Elsevier Science B.V. All rights reserved.
\end{abstract}

Keywords: Fibrous structured catalysts; Hydrodynamics; Multi-phase reactions; Bubble columns

\section{Introduction}

During the last few decades there has been a growing interest to chemical reactors with structured catalytic beds [1]. The optimal structure of a catalytic bed in three phase reactions leads to improved fluid dynamics, compared to traditional randomly fixed bed reactors. Defined flow conditions result in a uniform reactant distribution on the catalytic surface and a narrow distribution of the residence time. This allows for a better control of consecutive reactions and leads to an increase in product selectivity.

Structured catalysts prepared on the base of woven fibrous supports have already demonstrated high activity for gas-solid [2-6] and gas-liquid-solid [7-9] reactions. The open macrostructure and the mechanical flexibility of fibrous material provide new options for the design of multiphase reactors compared to traditional ceramic honeycomb monoliths.

\footnotetext{
* Corresponding author. Tel.: +41-21-693-3181; fax: +41-21-693-3190.

E-mail address: albert.renken@epfl.ch (A. Renken)
}

Bubble columns are common multiphase reactors used in various processes like catalytic oxidation of hydrocarbons, production of synthetic fuels, hydroformylation of olefins and catalytic hydrogenation of organic intermediates. Most bubble columns are designed as an empty cylinder where gaseous reactants are introduced at the bottom of the column and are contacted with the liquid-phase in which the solid catalyst is suspended. In general, the gas-phase flow pattern has plug-flow properties, while the mixture liquid/catalyst suspension demonstrates complete back mixing.

Various internals, such as tubes and trays are often packed into the column in order to modify the gas and liquid flow patterns, in order to optimise conversion and product selectivity. For such optimisation, knowledge of the reactor hydrodynamics is necessary along with the reaction network and detailed kinetics. Despite of the significant impact of internal packings on the performance of bubble columns, experimental studies of the hydrodynamics of staged bubble columns are very few.

During this work we studied the influence of horizontally placed trays of glass fibrous tissue on the hydrodynamic behaviour of a staged bubble column. The 
gas and liquid pass concurrently in an upstream flow through the reactor with the fibrous layers placed perpendicularly to the flow. In this way, the catalytic bed replaces the suspended catalyst powder. The reactor hydrodynamics is characterised by the liquid hold-up and the pressure drop through the catalytic bed as a function of fibrous catalyst structure and gas/liquid superficial velocities. Experimental studies of hydrodynamics were completed by the simulations based on empirical equations. The obtained parameters were also estimated for the isopropanol/hydrogen system commonly used in hydrogenation reactions.

\section{Experimental}

\subsection{Main characteristics of glass fibre materials}

Woven fabrics made of E-type glass fibres (EGF) were used as a prototype of the catalytic layers for hydrodynamic studies in structured catalytic bed reactors. The specific surface area (SSA) of the materials, received from Vetrotex, France SA, was measured by $\mathrm{N}_{2}$ adsorption-desorption at $77 \mathrm{~K}$ using a Sorptomatic 1990 (Carlo Erba) instrument. For the measurements woven samples were used. The SSA of the samples was calculated employing the BET method and found to be about $2 \mathrm{~m}^{2} / \mathrm{g}$.

The glass fibre fabrics are woven from threads (diameter $D$ ) consisting of elementary filaments with a diameter $d$ of 3-10 $\mu \mathrm{m}$. Fabrics of different woven structures used in the study are shown in Fig. 1. Their characteristics are summarised in Table 1. The open area $A_{0}$ is expressed as the percentage of the open surface between the threads referred to the total fabric surface.

\subsection{Experimental set-up and procedure}

The reactor used for hydrodynamics studies is shown schematically in Fig. 2. The reactor consists of

Table 1

Structural parameters of the fabrics

\begin{tabular}{llll}
\hline Fabric & $\begin{array}{l}\text { Thread diameter } \\
D(\mathrm{~mm})\end{array}$ & $\begin{array}{l}\text { Distance between } \\
\text { thread } w(\mathrm{~mm})\end{array}$ & $\begin{array}{l}\text { Open area } \\
A_{0}(\%)\end{array}$ \\
\hline f-w0.3 & 0.3 & 0.3 & 25 \\
f-w0.6 & 0.7 & 0.6 & 25 \\
f-w1.3 & 2.4 & 1.3 & 15 \\
\hline
\end{tabular}

fabric f-w0.3
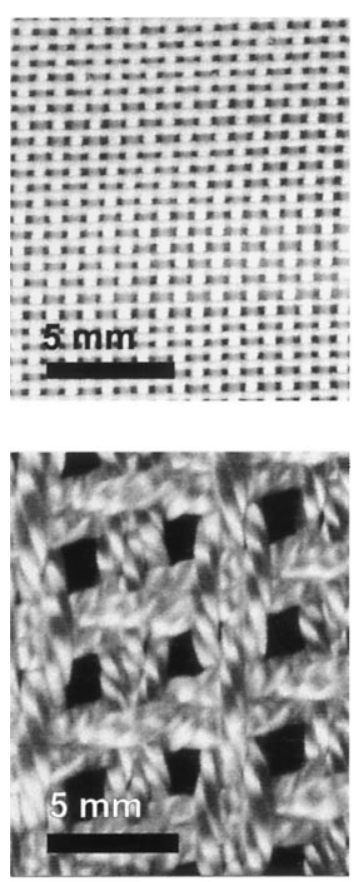

fabric f-w1.3 fabric f-w0.6
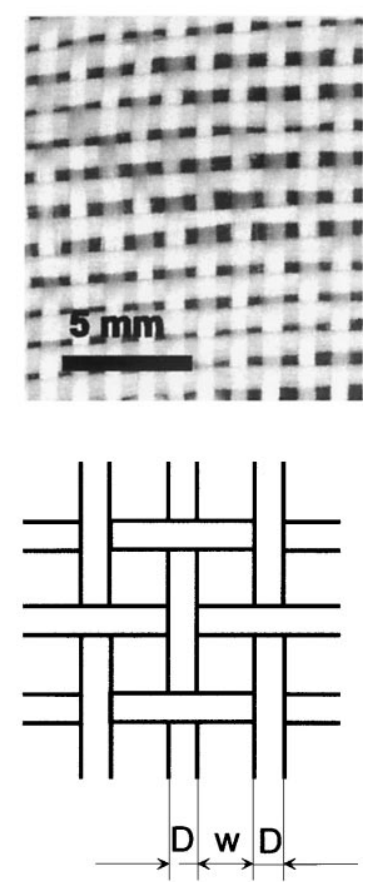

Fig. 1. Different structures of glass fibrous materials.

13 acrylic hollow cylinders with $24 \mathrm{~mm}$ inner diameter (ID) and $15 \mathrm{~mm}$ height. The conical inlet and outlet sections were filled with $2 \mathrm{~mm}$ glass beads in order to obtain a homogeneous gas/liquid distribution. Water and air flow concurrently upwards. The feed was

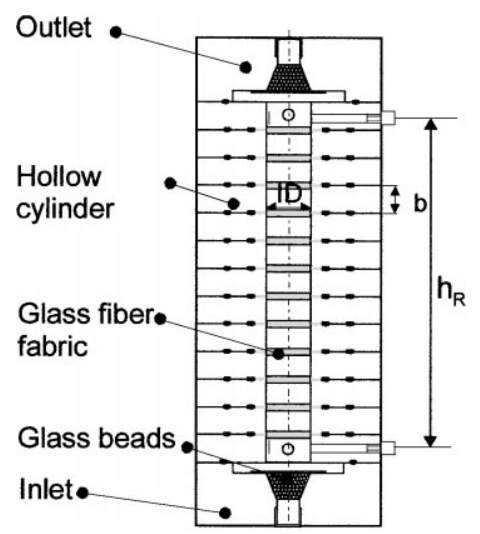

Fig. 2. Scheme of the reactor used for the hydrodynamics studies. 
Table 2

Physical properties of the fluids, based on the data of [11]

\begin{tabular}{lcl}
\hline & $\begin{array}{c}\text { Density } \\
\rho\left(\mathrm{kg} / \mathrm{m}^{3}\right)\end{array}$ & $\begin{array}{l}\text { Dynamic viscosity } \\
v\left(\mathrm{~m}^{2} / \mathrm{s}\right)\end{array}$ \\
\hline Air (293 K; 1 bar) & 1.20 & $1.5 \times 10^{-5}$ \\
Hydrogen (323 K; 7 bar) & 0.52 & $1.8 \times 10^{-5}$ \\
Water (293 K; 1 bar) & 1000 & $1.0 \times 10^{-6}$ \\
Isopropanol (303 K; 7 bar) & 786 & $2.3 \times 10^{-6}$ \\
\hline
\end{tabular}

controlled by flow meters (Vögtlin, Switzerland). Within the reactor, the fibrous layers were fixed between two acrylic cylinders. Various distances between layers $b$ were used: $60 \mathrm{~mm}$ (2 fabrics), $30 \mathrm{~mm}$ (6 fabrics) and $15 \mathrm{~mm}$ (12 fabrics).

The dynamic liquid hold-up $\beta_{1}$ was estimated from the measured mean residence time $\tau$, the liquid volume flow $\mathrm{Q}_{1}$ and the reactor volume $V_{\mathrm{R}}$ :

$\beta_{1}=\frac{V_{1, \text { holdup }}}{V_{\mathrm{R}}}=\frac{Q_{1} \tau}{V_{\mathrm{R}}}$

For the pressure drop measurements the reactor was connected to a water-filled U-tube. The frictional pressure drop $\Delta p_{\mathrm{f}}$ for the gas-liquid flow was calculated from the measured total pressure drop $\Delta p_{\text {tot }}$ as follows:

$\Delta p_{\mathrm{f}}=\Delta p_{\mathrm{tot}}-\rho_{1} g h_{\mathrm{R}} \beta_{1}$

The physical fluid properties for the air/water and isopropanol/hydrogen systems, which are typical for the hydrogenation reactions, are summarised in Table 2.

\section{Results and discussion}

\subsection{Phenomenological observations of gas/liquid flow}

In Fig. 3 the observed gas-liquid distributions are schematically shown for the reactor packed with fibrous layers. The layers redistribute the gas-phase in bubbles over the whole reactor cross-section. Gas/liquid distribution in the reactor strongly depends on the flow rates.

For low superficial gas velocities $u_{\mathrm{g} 0}\left(u_{\mathrm{g} 0} / u_{10}<10\right)$ and a distance between layers $b$ of 15-30 mm (Fig. 3a), the liquid-phase was observed to be a continuous phase and the gas was dispersed in small bubbles. This flow pattern is called 'bubble flow'. Below the fibrous layers small bubbles coalesce and form a gas pad. Increasing the superficial gas velocity $u_{\mathrm{g} 0}$ leads to larger diameters of the gas bubbles (Fig. 3b) until the gas-phase becomes the continuous phase (Fig. 3c). This flow pattern is reached for a gas/liquid velocity ratio of $u_{\mathrm{g} 0} / u_{10} \geq 100$ and corresponds to an 'annular flow' observed in empty tubes. Here the main part of the liquid is flowing as a film along the reactor wall [10]. In contrast to this 'annular flow' observed in conventional bubble columns, the liquid was observed above the fabrics. It should be noted that this indicates a direct transition from 'bubble flow' to a flow pattern similar to 'annular flow' without passing a 'slug or churn flow' as observed by Taitle et al. [10]. This can be explained by the short distances between the fibrous layers, which are in the range of the ID of the reactor (or less). Due to the short distances between the layers the gas bubbles are redistributed on the next fabric before they coalesce.
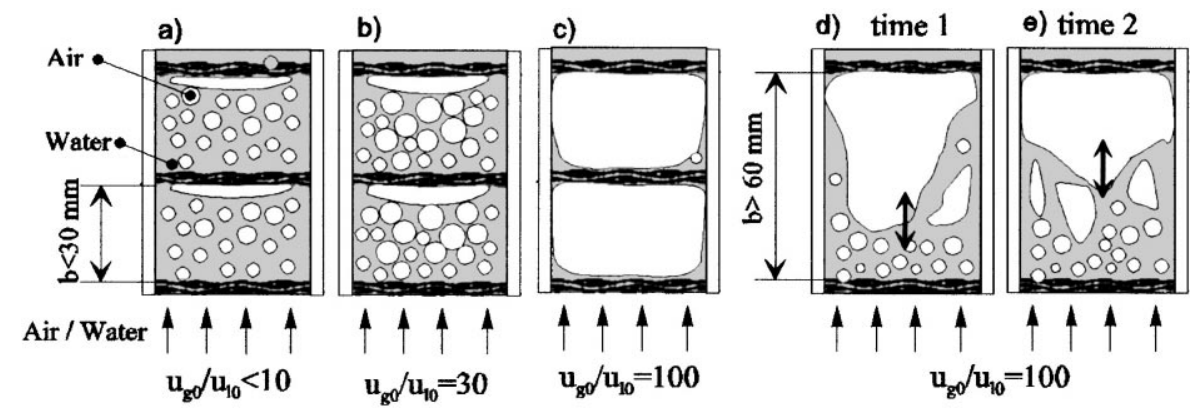

Fig. 3. Schematic presentation of gas/liquid distribution by fibrous catalytic layers in a bubble column $\left(u_{10}=0.61 \mathrm{~cm} / \mathrm{s}\right)$. 
'Slug and churn flow' regime was observed for layers at more than $60 \mathrm{~mm}$ distance from each other. The alternating up/down of the liquid slugs leads to a chaotic behaviour as indicated in Fig. $3 \mathrm{~d}$ and e.

For a suitable application in a reactor, we suggest a velocity ratio of $u_{\mathrm{g} 0} / u_{10}<30$ combined with a distance between layers $b$ smaller than the column diameter. Under these conditions, 'bubble flow' can be expected, leading to a good gas/liquid distribution on the fibrous catalytic layer and high gas/liquid interfacial area.

\subsection{Pressure drop}

In Fig. 4, the frictional pressure drop $\Delta p_{\mathrm{f}}$ for a structured catalytic bed is presented as a function of the superficial gas velocity $u_{\mathrm{g} 0}$ for different fabrics. The pressure drop $\Delta p_{\mathrm{f}}$ increases rapidly at low superficial gas velocities $u_{\mathrm{g} 0}$ and tents to a constant value at high gas velocities. A variation of the liquid superficial velocity $u_{10}$ was observed to affect $\Delta p_{\mathrm{f}}$ only slightly as shown for the fabric f-w0.3 as an example.

The frictional pressure drop $\Delta p_{\mathrm{f}}$ strongly depends on the width $w$ of the fabrics. For the same gas velocity of $u_{\mathrm{g} 0}=30 \mathrm{~cm} / \mathrm{s}$ and a superficial liquid velocity of $u_{10}=0.61 \mathrm{~cm} / \mathrm{s}$, the pressure drop $\Delta p_{\mathrm{f}}$ for the catalytic bed with fabrics of type f-w0.6 was higher than a factor of two compared to the bed with fabrics of type f-w1.3. A width of $w=0.3 \mathrm{~mm}$ (fabric type f-w0.3) leads to a pressure drop about seven times higher, compared to the bed with fabrics of type f-w1.3. The open

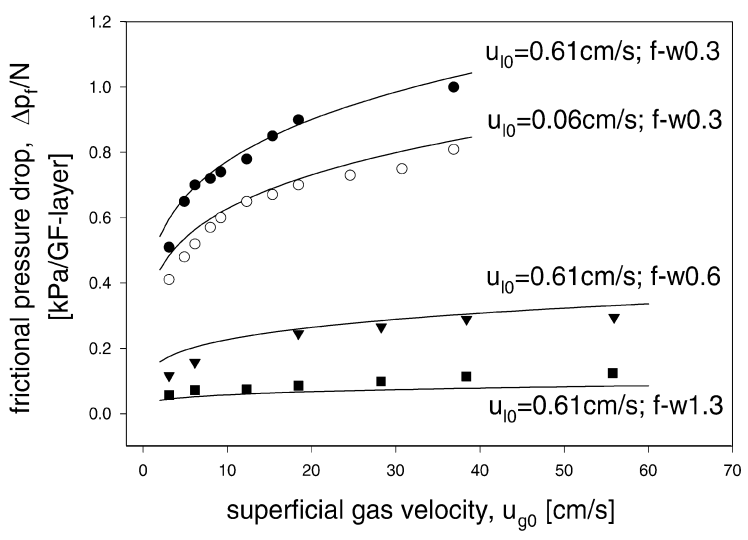

Fig. 4. Frictional pressure drop $\Delta p_{\mathrm{f}}$ as a function of gas superficial velocity $u_{\mathrm{g} 0}$ for different types of fabrics and for different liquid superficial velocities $u_{10}$. area $A_{0}$ of the fabrics was not observed to influence significantly the measured $\Delta p_{\mathrm{f}}$.

According to empirical correlation [12] for packed bubble columns, the pressure drop $\Delta p_{\mathrm{f}}$ in the plated bubble column can be estimated:

$\frac{\Delta p_{\mathrm{f}}}{N}=A \operatorname{Re}_{\mathrm{G}}^{B} \operatorname{Re}_{\mathrm{L}}^{C}\left(\frac{w}{d_{\mathrm{c}}}\right)^{D}$

Contrary to the packed bubble columns, which can be considered as quasi-homogeneous systems, the plated bubble-column with fibre fabrics can be considered as a staged column. The fibrous layers separate the column in $N$ stages, for which an identical pressure drop is assumed. Based on the results of 72 experiments the model parameters $A-D$ were estimated: $A=1.44 \times 10^{-3} \mathrm{kPa} ; B=0.22 ; C=0.09 ; D=-1.77$. Experimental and predicted data are compared in Fig. 4.

Correlative Eq. (4) can be used to estimate the pressure drop for different gas/liquid systems. Based on the physical properties of the isopropanol/water-hydrogen system in Table 2, it is possible to predict a $10 \%$ smaller pressure drop compared to the water/air system.

$$
\begin{aligned}
\frac{\Delta p_{\mathrm{f}, \mathrm{H}_{2} / \text { isoprop }}}{\Delta p_{\mathrm{f}, \text { air } / \text { water }}} & =\left(\frac{\mathrm{Re}_{\mathrm{H}_{2}}}{\mathrm{Re}_{\text {air }}}\right)^{B}\left(\frac{\mathrm{Re}_{\text {isopro }}}{\mathrm{Re}_{\text {water }}}\right)^{C} \\
& =\left(\frac{v_{\text {air }}}{v_{\mathrm{H}_{2}}}\right)^{0.22}\left(\frac{v_{\text {water }}}{v_{\text {isoprp }}}\right)^{0.09}
\end{aligned}
$$

\subsection{Liquid hold-up}

In Fig. 5 the liquid hold-up $\beta_{1}$ is presented as a function of the liquid superficial velocity $u_{10}$ for different tissue structures. A higher liquid hold-up $\beta_{1}$ is obtained for lager width $w$. This observation can be explained by the preferred formation of gas pads below dense fabrics.

The liquid hold-up $\beta_{1}$ can be described with the empirical correlation (5). The coefficients were estimated based on 58 experiments covering the following parameters: $u_{10}=0.31-1.54 \mathrm{~cm} / \mathrm{s}, u_{\mathrm{g} 0}=3-55 \mathrm{~cm} / \mathrm{s}$ and $w=0.3 / 0.6 / 1.3 \mathrm{~mm}$. According to Eq. (6) the liquid hold-up $\beta_{1}$ of the hydrogenation reaction system differs only slightly from the air/water system.

$\beta_{1}=1.1 \operatorname{Re}_{\mathrm{G}}^{-0.35} \operatorname{Re}_{\mathrm{L}}^{0.25}\left(\frac{w}{d_{\mathrm{c}}}\right)^{0.18}$ 


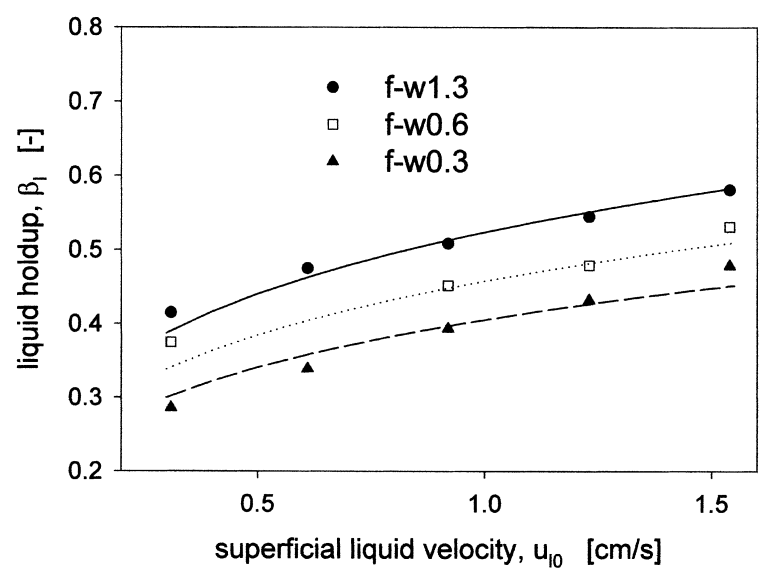

Fig. 5. Liquid hold-up $\beta_{1}$ versus liquid superficial velocity $u_{10}$ for three different fabric geometries $\left(u_{\mathrm{g} 0}=6.1 \mathrm{~cm} / \mathrm{s}\right)$.

$$
\frac{\beta_{1, \mathrm{H}_{2} / \text { isopro }}}{\beta_{1, \text { air } / \text { water }}}=\left(\frac{\nu_{\text {air }}}{v_{\mathrm{H}_{2}}}\right)^{-0.35}\left(\frac{v_{\text {water }}}{v_{\text {isopro }}}\right)^{0.25}=0.87
$$

\section{Conclusions}

1. Woven fibrous materials are suggested as innovative reactor design with structured catalytic beds for three-phase catalytic reactions. The hydrodynamics of the reactor as a staged bubble column with glass fibre layers was studied for water/air up-flow system.

2. Three different flow regimes were observed in a structured staged bubble column:

- a 'bubble flow' with a redistribution of gas-phase over every fibrous layer was seen at gas/liquid velocity ratio $u_{\mathrm{g} 0} / u_{10}<30$ and for the distance between layers smaller than the column diameter;

- an 'annular flow' regime above the fabrics;

- a 'slug and churn flow' regime for layers with a distance of more than $60 \mathrm{~mm}$ from each other.

3. The hydrodynamic parameters, like pressure drop $\Delta p_{\mathrm{f}}$ and liquid hold-up $\beta_{1}$ were found to be dependent on the woven structure of fibrous layers, mainly on the distance between threads.

4. The experimental results were modelled by means of empirical equations involving dimensionless parameters (Reynolds numbers for liquid and gas, $\operatorname{Re}_{\mathrm{L}}$ and $\left.\mathrm{Re}_{\mathrm{G}}\right)$. Based on the proposed equations the pressure drop, $\Delta p_{\mathrm{f}}$ and liquid hold-up, $\beta_{1}$ can be estimated for different liquid/gas systems.

\section{Nomenclature}

\begin{tabular}{|c|c|}
\hline$A_{0}$ & $\begin{array}{l}\text { open area of the glass fibre fabrics } \\
\text { (dimensionless) }\end{array}$ \\
\hline$b$ & $\begin{array}{l}\text { distance between the fibre fabrics in the } \\
\text { reactor }(\mathrm{mm})\end{array}$ \\
\hline$d$ & filament diameter (mm) \\
\hline$D$ & thread diameter (mm) \\
\hline$g$ & gravity constant $\left(\mathrm{m} / \mathrm{s}^{2}\right)$ \\
\hline$h_{\mathrm{R}}$ & $\begin{array}{l}\text { distance between the U-tube connections } \\
(\mathrm{mm})\end{array}$ \\
\hline ID & inner diameter of the reactor $(\mathrm{mm})$ \\
\hline$m$ & mass $(\mathrm{g})$ \\
\hline$N$ & $\begin{array}{l}\text { number of horizontal fabric layers in a } \\
\text { reactor (dimensionless) }\end{array}$ \\
\hline$p$ & pressure $(\mathrm{Pa})$ \\
\hline$\Delta p_{\mathrm{f}}$ & frictional pressure drop $(\mathrm{Pa})$ \\
\hline$\Delta p_{\text {tot }}$ & total pressure drop $(\mathrm{Pa})$ \\
\hline$Q_{1}$ & liquid volume flow (1/s) \\
\hline$u_{\mathrm{g} 0}$ & superficial gas velocity $(\mathrm{cm} / \mathrm{s})$ \\
\hline$u_{10}$ & superficial liquid velocity $(\mathrm{cm} / \mathrm{s})$ \\
\hline$V_{1, \text { hold-up }}$ & $\begin{array}{l}\text { volume of the liquid hold-up in the } \\
\text { reactor (1) }\end{array}$ \\
\hline$V_{\mathrm{R}}$ & reactor volume (1) \\
\hline$w$ & distance between the threads, width \\
\hline
\end{tabular}

\section{Greek symbols}

$\beta_{1} \quad$ liquid hold-up (dimensionless)

$\rho_{1} \quad$ liquid density $\left(\mathrm{kg} / \mathrm{m}^{3}\right)$

$\tau \quad$ mean residence time (s)

$v$ kinematic viscosity

\section{Acknowledgements}

The financial support provided for this work by the Swiss National Science Foundation and the Max-Buchner-Forschungsstiftung is gratefully acknowledged.

\section{References}

[1] A. Cybulski, J. Moulijn (Eds.), Structured Catalysts and Reactors, Chemical Industry, New York, Vol. 71, 1998. 
[2] D.M. Nicholas, Y.T. Shah, I.A. Zlochower, Indian Chem. Prod. Res. Dev. 15 (1976) 29.

[3] A.K. Neyestanaki, L.-E. Lindfors, Combust. Sci. Technol. 110/111 (1995) 303.

[4] L. Kiwi-Minsker, I. Yuranov, B. Siebenhaar, A. Renken, Glass fiber catalysts for total oxidation of $\mathrm{CO}$ and hydrocarbons in waste gases, Catal. Today (1998), 54 (1999) 39-46.

[5] I. Yuranov, L. Kiwi-Minsker, V. Barelko, A. Renken, in: K.G.F. Froment, C. Waugh (Vol. Eds.), Reaction Kinetics and the Development of Catalytic Processes, in: J.T.Y.B. Delmon (Ser. Ed.), Studies in Surface Science and Catalysis, Vol. 122, Elsevier, Brugge, 1999, pp. 191-198.

[6] L. Kiwi-Minsker, I. Yuranov, E. Slavinskaia, V. Zaikovskii, A. Renken, Pt and Pd supported on glass fibers as effective combustion catalysts, Catal. Today (2000), in press.
[7] L. Kiwi-Minsker, I. Yuranov, V. Höller, A. Renken, Chem. Eng. Sci. 54 (1999) 4785-4790.

[8] V. Höller, D. Wegricht, I. Yuranov, L. Kiwi-Minsker, A. Renken, Three-phase nitrobenzene hydrogenation over supported glass fiber catalysts: reaction kinetics study, Chem. Eng. Technol. 23 (2000) 251-255.

[9] V.V. Barelko, V.G. Dorohov, A.A. Fomin, S.I. Serdyukov, M.S. Safonov, B.S. Balzinimaev, Europacat IV, Book of Abstracts, 1999, p. 828.

[10] Y. Taitel, D. Bornea, A.E. Dukler, AIChE J. 26 (1980) 345.

[11] Handbook of Chemistry and Physics, CRC Press, Boca Raton, 1981.

[12] W.-D. Deckwer, Reaktionstechnik in Blasensäulen, Sall \& Sauerländer, 1985. 